\title{
Maffucci Syndrome
}

YEN-PO TSAO, MD, Taipei Veterans General Hospital; CHANG-YOUH TSAI, MD, PhD, Taipei Veterans General Hospital, and National Yang-Ming University; WEI-SHENG CHEN, MD, Taipei Veterans General Hospital, and National Yang-Ming University, Taipei, Taiwan. Address correspondence to Dr. W.S. Chen, No. 201, Sec. 2, Shi-Pai Road, Taipei 112, Taiwan. E-mail: weisheng0112@gmail.com. J Rheumatol 2015;42:2434-5;

doi:10.3899/jrheum.150216

Maffucci syndrome is a rare disease involving multiple enchondromatosis and cavernous hemangiomas of the dermis, subcutis, or internal organs. Enchondromas can lead to deformity or fractures.

A 51-year-old man who was diagnosed with Maffucci syndrome at age 10 presented for curettage of an enchondroma and a bone graft in the right proximal phalanx of the thumb and the right third metatarsal bone, and excision of a large hemangioma on the left palm. The asymmetric distribution of enchondromas and hemangiomas was apparent. In particular, there were more hemangiomas on the right hand (Figure 1), and radiograph indicated enchondromas at the first, fourth, and fifth digits of the left hand and the second digit of the right hand with radiolucency and destruction of the cortex. The left hand had increased soft tissue with hemangiomas and phleboliths inside (Figure 2A). Sonography of these hemangiomas revealed small calcified spots and surrounding anechoic lesions (Figure 2B).
Maffucci syndrome is a rare disease first reported in 1881 and is characterized by multiple enchondromatosis and cavernous hemangiomas of the dermis, subcutis, or internal organs at birth or in early childhood ${ }^{1}$. Enchondromas in the metaphyseal regions of long bones may also result in deformity and limb asymmetry, as well as pathological fractures ${ }^{1}$. Maffucci syndrome should be differentiated from Ollier disease, which is characterized by enchondromatosis alone. Both diseases are associated with somatic mutations of isocitrate dehydrogenase 1 or $2^{2,3,4}$. Close followup of the patient is necessary because of the increasing risk of malignancies, including pancreatic adnocarcinoma, brain glioma, and chondrosarcoma ${ }^{5}$. No medical care is needed if a patient is asymptomatic, and surgical intervention should be considered when treating fractures or associated neoplasms.

\section{REFERENCES}

1. Bovee JV, Alman BA. Enchondromatosis: Ollier disease and

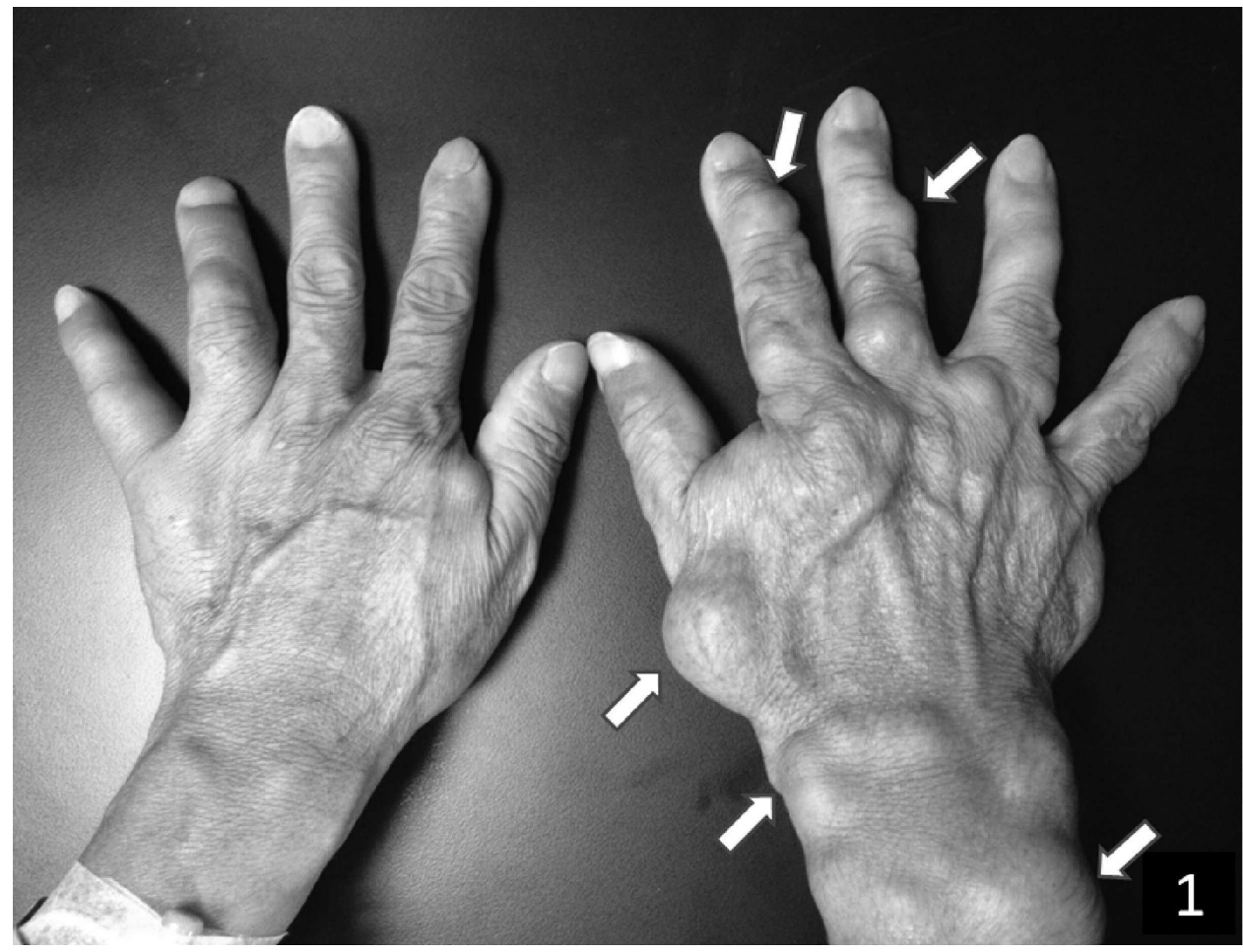

Figure 1. The asymmetric distribution of enchondroma and hemangioma was apparent, with more hemangiomas in the right hand. 


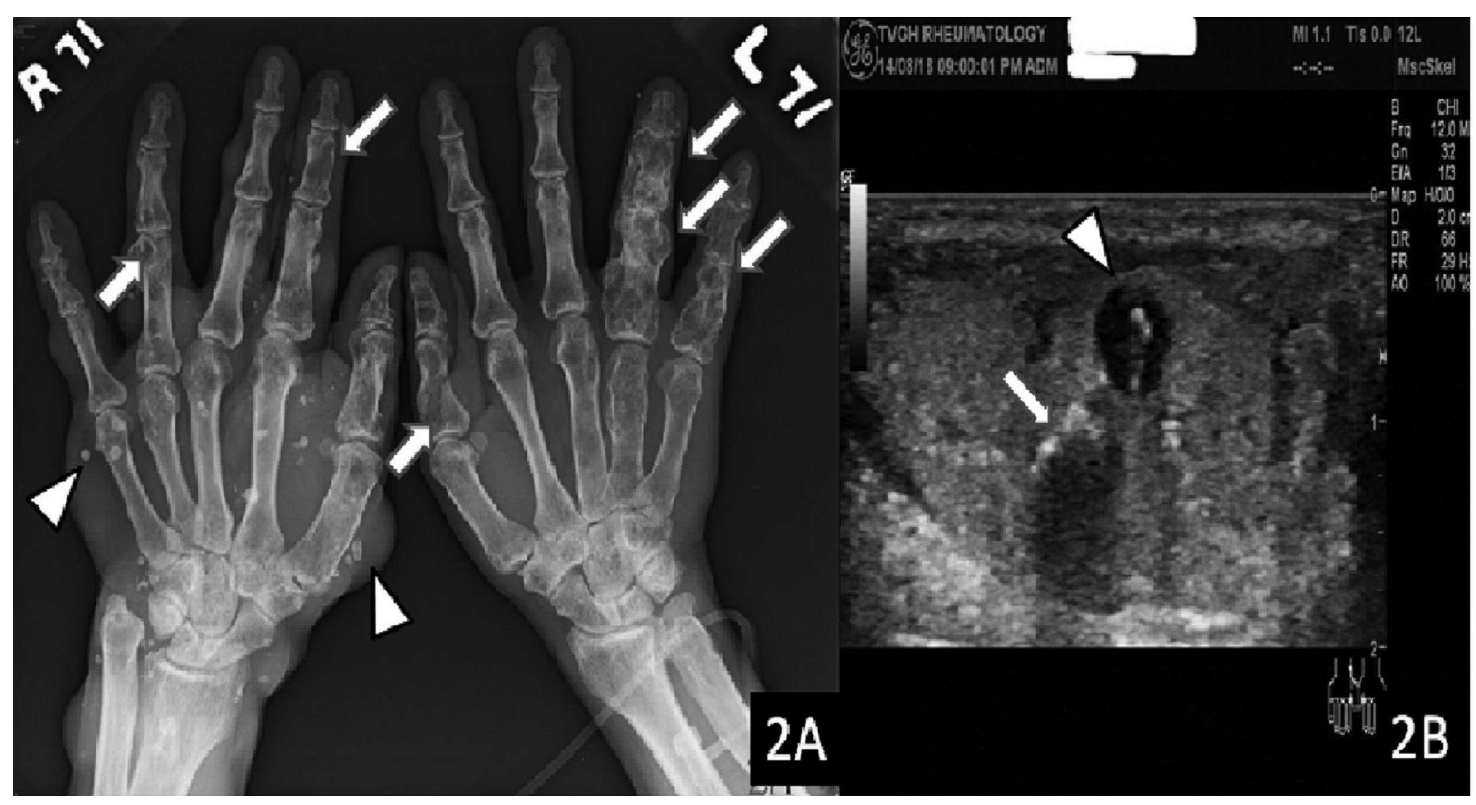

Figure 2. A. Radiograph revealed increasing soft tissue that were hemangiomas with phleboliths (arrowhead) inside over right hand. Arrows indicate enchondromas with radiolucency and destruction of the cortex. B. Ultrasonography showed these hemangiomas with small calcified spots (arrow) or with surrounding anechoic lesions (arrowhead).

Maffucci syndrome. In: Fletcher CD, Hogendoorn P, editors. WHO classification of tumours of soft tissue and bone, 4th ed. Lyon: IARC Press; 2013:376-8.

2. Pansuriya TC, van Eijk R, d'Adamo P, van Ruler MA, Kuijjer ML, Oosting J, et al. Somatic mosaic IDH1 and IDH2 mutations are associated with enchondroma and spindle cell hemangioma in Ollier disease and Maffucci syndrome. Nat Genet 2011;43:1256-61.

3. Amary MF, Damato S, Halai D, Eskandarpour M, Berisha F, Bonar F, et al. Ollier disease and Maffucci syndrome are caused by somatic mosaic mutations of IDH1 and IDH2. Nat Genet 2011;43:1262-5
4. Amary MF, Bacsi K, Maggiani F, Damato S, Halai D, Berisha F, et al. IDH1 and IDH2 mutations are frequent events in central chondrosarcoma and central and periosteal chondromas but not in other mesenchymal tumours. J Pathol 2011;224:334-43.

5. Verdegaal SH, Bovée JV, Pansuriya TC, Grimer RJ, Ozger H, Jutte $\mathrm{PC}$, et al. Incidence, predictive factors, and prognosis of chondrosarcoma in patients with Ollier disease and Maffucci syndrome: an international multicenter study of 161 patients. Oncologist 2011;16:1771-9. 